\title{
LONG-TERM WATER RESOURCE MANAGEMENT IN SEMI-ARID AREAS: A SOUTH AFRICAN CASE STUDY
}

\author{
W.J. DE LANGE ${ }^{1} \&$ T.E. KLEYNHANS ${ }^{2}$ \\ ${ }^{1}$ Council for Scientific and Industrial Research, South Africa. \\ ${ }^{2}$ Department of Agricultural Economics, Stellenbosch University, South Africa.
}

\begin{abstract}
Fresh water resources provide a platform for complex and often emotional issues to develop, particularly in resource scarcity situations. Bulk-water infrastructure contains elements of a public good and has proved vulnerable to failures in market and government driven allocation strategies. Common to both are uncaptured costs and benefits due to shortcomings in cost quantification techniques. Natural ecosystems stand to lose the most since ecosystem services are often not quantifiable in monetary terms and therefore neglected in allocation decision-making. This study took on the challenge of expanding current decision-support to promote more inclusive long-term water management. A case-study approach with the focus on a choice related problem regarding different long-term bulk-water resource management options was applied in the Western Cape province. The study incorporated components of economic valuation theory, a public survey and a modified Delphi expert panel technique. Both spatial and temporal dimensions of the decision-making context were expanded. Two surveys were completed to accommodate these expansions. The first focused on public preference in water allocation management and the relative merit of accommodating public preference in highly specialised decision-making such as long-term water allocation decision-making. The second survey utilised a modified Delphi technique in which an expert panel indicated the relative merit of two alternative long-term allocation strategies. A willingness to pay for 'greener' water was observed and may be used to motivate a paradigm shift from the management's perspective to consider, without fear of harming their own political position, 'greener' water supply options more seriously even if these options imply higher direct costs to the public.
\end{abstract}

Keywords: decision-support, public participation, water management.

\section{INTRODUCTION}

Natural and environmental assets provide the basis for economic activity and social well-being. It is often the case that the relative values of these assets cannot be quantified at a satisfactorily level of significance in monetary terms. This implies that the value of such assets is at best vaguely accounted for, or at worst, completely ignored in resource management decision-making processes.

The inability to confidently estimate total costs and benefits of different allocation distributions promotes failures in market- and government-orientated allocation systems. With new bulk supply sources becoming less accessible, more expensive and environmentally less acceptable, new and innovative water management strategies and policies are called for. The aim of this study is to improve decision support such as multi-criteria decision-making (MCDM) to promote more inclusive resource management decision-making in practice via the expansion of the decision-making context. This was applied in the bulk-water allocation decision-making environment of the Berg Water Management Area (BWMA) in South Africa.

\section{PROBLEM STRUCTURING AND METHODOLOGY}

The development of bulk water augmentation infrastructure aims to re-allocate water between different areas, uses and users for different reasons. Such re-allocations are often motivated by price elasticity of demand differentiations with the emphasis on financial, political and technological impacts. Socio-economics and environmental impacts of allocation decisions are often overlooked 


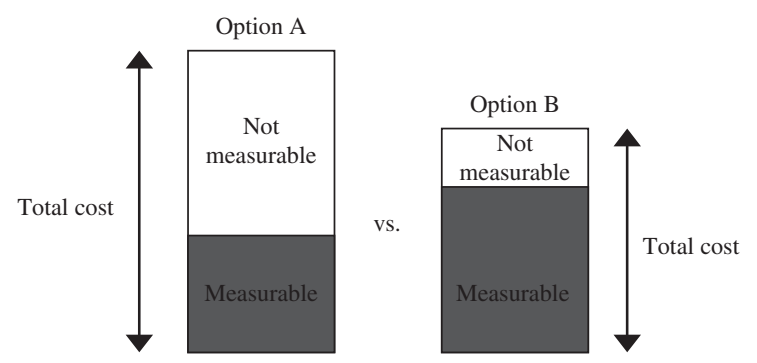

Figure 1: A measurement problem.

leading to ignorance of some potentially crucial impacts of resource allocation decision-making. It consequently defines a 'measurement problem' as illustrated in Fig. 1. Preference is often given to the 'highest and best use' argument in resource scarcity situations; that is, the perceived value of water use in urban areas exceeds rural use and a gradual re-allocation of water from rural to urban areas is therefore expected [1]. The rural periphery offers a significant value which is not accommodated in the decision-making process. The measurement problem, therefore, narrows the allocation decision-making context and as such, social welfare is unknowingly threatened.

Markets have become popular resource allocation mechanisms [2-14]. Such systems sufficiently accommodate individual allocation decision-making, but often fail with public goods since social gains/losses are mostly not accounted for in private allocation decision-making [15, 16]. Unfortunately, the differences in perceived value are not fully quantifiable and therefore not fully accounted for in market-driven allocation systems [17-19]. Such systems could, therefore, not be exclusively used to achieve sustainable water resource allocations and care should be taken to promote the market as the best water allocation mechanism.

An opportunity for government involvement to account for market failures of public goods is consequently created. However, the 'measurement problem', together with vulnerability to lobby groups, hidden agendas and the tendency of using own discretion (which often leads to the misuse of power), results in government failure; hence the need exists to aid government intervention measures that ensure the promotion of social welfare maximisation [17, 18, 20, 21]. Government does, however, require decision-support to confront complexities associated with allocation decisions, i.e. accounting for different climatic, socio-economic and political contexts, both over the short and long term.

Decision-support is directly related to explaining decision-making behaviour. To justify and explain behaviour, rational choice theory appeals to three distinct elements in the choice situation. First, there is the feasible set (i.e. the set of all courses of action that satisfy various logical, physical and economic constraints). Second is the causal structure or interactions between actions and outcomes. The third element is a ranking of the feasible alternatives, usually derived from a ranking of the outcomes to which they are expected to lead. To make a rational decision, then, simply means to choose the highest ranked element in the feasible set [22, 23]. Decision-support systems do not solve this decision-making problem, but provide insight and creativity to aid decision makers in the process of making 'better' decisions [23, 24]. MCDM came to the fore as a system that provides a rational and consistent approach to rank and compare water management alternatives [24].

Essentially, MCDM is both a process and a methodology that compares management alternatives from different points of view (criteria). It employs these criteria to create weighted scores for an overall ranking of different management alternatives. The process facilitates greater understanding 
of the management problem, involved parties, and their priorities, values and objectives. Through exploring these in the context of the problem, it guides decision-makers in identifying a preferred course of action since the method is sensitive to the different contexts of the same problem and its different stakeholders [23]. It does not provide a 'correct' or 'true' system of weights or scores because these are determined by the inputs of stakeholders in the decision-making process [25-27]. The weight structure between criteria reflects the trade-offs society is willing to make and relates to the level of potential conflict between criteria and stakeholders on that criterion [23, 24]. MCDM certainly does not neutralise decision-making subjectivity; it only makes the need for subjective judgements explicit, and therefore, the decision-making process more transparent by forcing decision-makers to at least consider difficult trade-offs [25-27]. Transparency is, therefore, of utmost importance since it promotes stakeholder participation, especially in cases where multiple stakeholders are involved, as is the case in water resource allocation management.

Management alternatives contain trade-offs, which are determined by utility functions, i.e. there will be different 'winners' and 'losers' for different management alternatives. Finding a balance that will promote social welfare maximisation is the challenge decision-makers face and decisionmaking regarding such a balance is done with the aid of differentiation criteria. Within the context of this study, we will assume that a criterion is a means or a standard of judging [23], i.e. some pre-defined standard by which one particular choice could be compared with another. MCDM facilitates clear and objective thinking regarding quantification of these trade-offs. It has a facilitative role and does not intend to guarantee total objectivity and the 'correct' decision since decisions are most of the time context bound. MCDM does, however, integrate objective measurement with value judgements and, therefore, makes subjectivity more explicit and manageable.

Different approaches to MCDM could be followed [23, 24]:

- Utility and value function approaches among which multi-attribute utility theory (MAUT) and analytical hierarchy process (AHP) are the best known in South Africa. These approaches first assess marginal utilities and then combine these into an overall utility function representing overall strength of preference among options. MAUT is the only technique that addresses uncertainty in its axiomatic framework by analysing the expected values. AHP assesses marginal utilities by asking for the relative strengths of preferences between each pair of possible scenarios. AHP is useful, simple and, consequently, a widely used tool.

- Goal programming and reference point techniques are the original formal forms of MCDM techniques. Goal programming searches for the scenario that minimises a measure of underachievement of goals. The idea is that once a solution is found, the decision-maker will review his or her goals, and the process will repeat itself until no significant gains are realised [24]. Reference point approaches start by having the decision maker specify achievement levels for each criterion in terms of relevant performance measures. These levels are typically of three types:

- goal levels (performance level that will fully satisfy the goals of the decision maker);

- exclusion levels (performance level at which, if violated, the entire scenario becomes unacceptable);

- reference levels (expectation of the decision-maker of an acceptable compromise between conflicting demands of different criteria.

- Outranking approaches represent evidence for and against the statement that one alternative is better than another. Alternative courses of action are compared in terms of different criteria to determine the extent to which a preference for one over the other can be asserted. In aggregating this preference information across all relevant criteria, the model seeks to establish the strength of evidence favouring the selection of one alternative over another. 
- Game theory approaches, in which each criterion can be associated with a single player, synthesise the utility functions of individual players into a social utility function. It assumes that each criterion is associated with a particular 'player' and that marginal utilities can be associated with each policy scenario [24]. Game theory aims at identifying solutions to the decision problem that represent the most acceptable compromise between players. Nash equilibriums, seeking the policy scenario that maximises the product of the marginal utilities, are the simplest forms of this type of solution.

- Interactive MCDM approaches imply a progressive evolution and definition of decision-makers' preferences through an interaction between them and the results generated from various runs of the model. This interaction becomes a dialogue in which the model responds to an initial set of the decision-maker's preferences or trade-offs, and then when this response has been examined, another set is offered, and thus, the procedure progresses in an interactive way and iterative way until the decision-maker has found a satisfactorily solution [24].

Different MCDM models include [23]:

- weighted average,

- preference ranking organisation method for enrichment evaluations,

- compromise programming,

- elimination choice translating reality,

- AHP.

The choice of specific method is critical in terms of appropriateness to the resource management problems because each method produces different rankings of the same set of management alternatives (feasible set) [23, 25, 28]. Selecting the most suitable MCDM requires testing different methods to reflect the decision-maker's evaluation weights, and of course, the validity of applying the method. This study employed the AHP approach to compare two different long-term water management strategies in the BWMA. These two strategies were compared against a criteria set that has been negotiated with selected experts in an interactive way. A scoring and weighing exercise followed by which a common aggregation function was derived that combines criterion scores and preference weights to calculate a comparative index for the two strategies ('development paths'). The main reasons for the choice were:

- The number of criteria made many of the other weighing methods infeasible.

- The method allows for many criteria to be simplified to individual comparison choices.

- The time constraints required each participant to the test (i.e. to perform comparisons) at the same time.

- The method has a strong theoretical foundation.

- Group and individual comparisons could be made to identify trends and potential trade offs.

As a point of criticism, the method does assume the decision-making problem at hand as given (i.e. it takes the starting point as a well defined problem and focuses on the evaluation). The method is, therefore, not geared towards analysing symptoms of underlying challenges or towards identifying the challenge that needs to be resolved.

\section{EXPANSION OF DECISION-SUPPORT}

A practical expansion to MCDM is needed for the promotion of inclusive decision-making on water resource management. Figure 2 presents expansions to both temporal and spatial dimensions of the decision-making context as proposed in this study. 


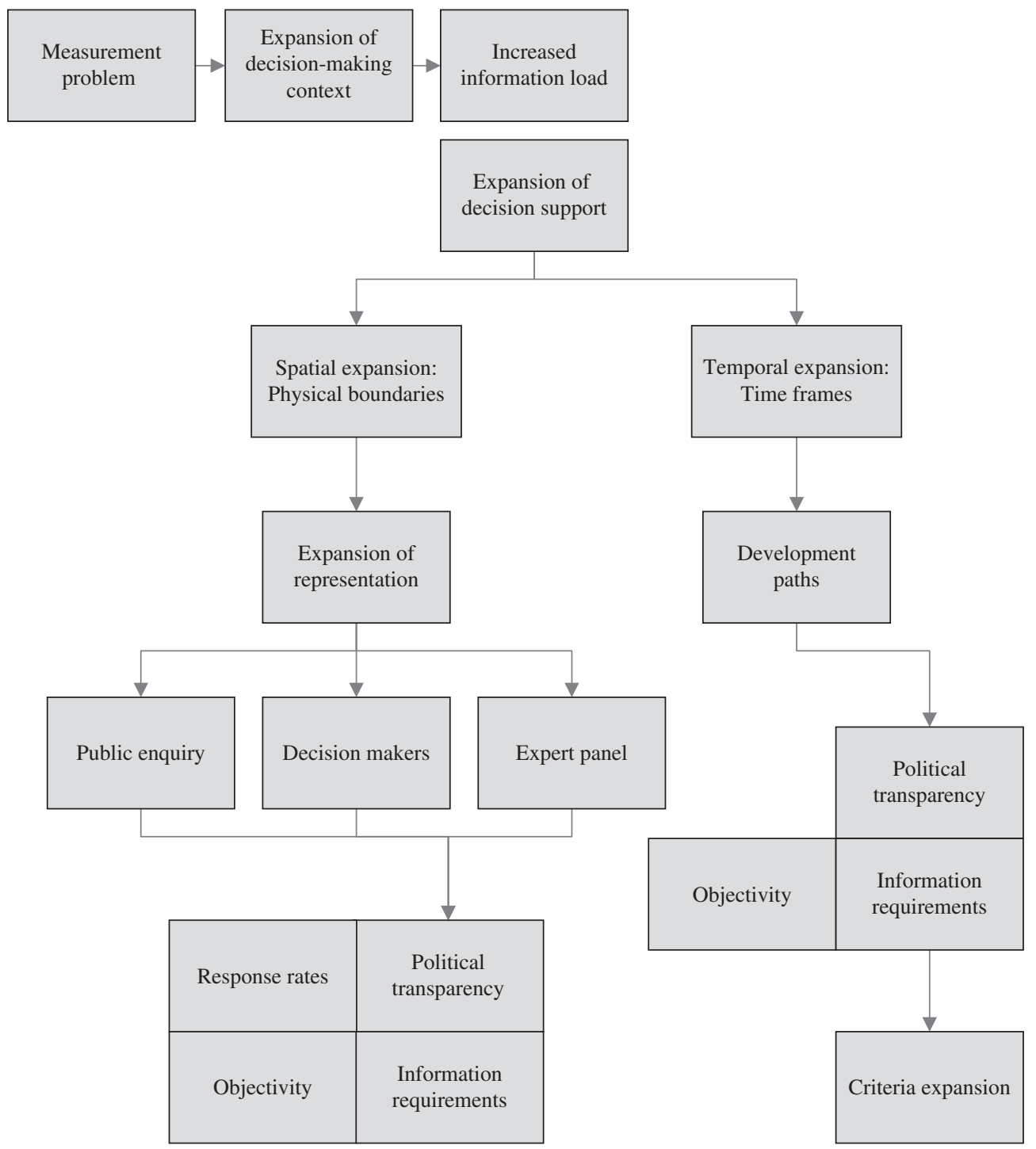

Figure 2: Expansion of decision-support.

These expansions were applied in bulk-water resource management in the BWMA, one of 19 management areas in South Africa. The area is characterised by a Mediterranean climate and strong deterministic water supply (winter rainfall) from April to August. Average rainfall is $348 \mathrm{~mm}$ per year with a significant variation ranging between $3000 \mathrm{~mm}$ per annum in the mountainous areas to $<300 \mathrm{~mm}$ per annum in the northwest of the area (see Fig. 3).

\subsection{Expanding the temporal dimension}

Expanding the temporal dimension will compel decision-makers to at least consider previously excluded long-term costs/benefits of different management options. The expansion was made 
tangible via the development of two sets of sequences of supply augmentation schemes ('development paths' - see Table 1) for the BWMA. Each sequence was constructed in an objective and transparent way via involvement of local government, service providers and consultation firms. Although still somewhat controversial, it does represent two legitimate alternative combinations of bulk supply schemes for long-term bulk-water supply development for the Western Cape Supply System. It is important to note that the focus is not on individual schemes, but on a development path as a whole and that each suggested outlay is not fixed and could be changed as new information (especially regarding costs) becomes available.

Development path A represents the more 'conventional' way of supplying future bulk-water needs in the BWMA. It incorporates all bulk-water supply schemes up to 2004 in the BWMA (including all water demand management strategies such as leakage repair, pressure control and user education) from where a typical storage expansion strategy is opted for.

Development path B poses an alternative, implementing 'expensive but potentially greener' bulk-water supply options at an earlier stage. This development path challenges current decisionmaking and cost-estimation methodologies by questioning the relative cost of current 'expensive' options compared to 'cheaper' alternatives. Development path B could also be seen as a structured argument for not increasing water re-allocations from rural to urban areas in the study area.

In practical terms, the main difference between paths $\mathrm{A}$ and $\mathrm{B}$ relates to the timing of 'more expensive' supply schemes such as the desalination of seawater or recycling to potable standard. Development path A contains more robust technology than B, while B is more sensitive to technological development than A; however, B has, therefore, greater potential in terms of efficiency gains with regard to technological development.

The challenge was to identify the long-term impacts of each path and to evaluate their relative legitimacy accordingly. It is therefore important to evaluate the two development paths as packages and not merely as a sequence of individual schemes. Within the expansion of the temporal dimension, new spatial dimensions came to the fore and, with that, additional socio-economic and ecological considerations, forcing decision-makers to think more broadly regarding the consequences of water management decisions.

\subsection{Spatial expansion}

Although not the only water user entity in the BWMA, the City of Cape Town (CCT) is by far the biggest (in terms of volume and number of users). It is estimated that more than $90 \%$ of the total annual water supply for the city is supplied form outside the municipal boundaries of the CCT, the CCT is therefore dependent on the surrounding rural areas for its water supply. Water allocations within the administrative boundaries of the CCT (and even within the BWMA for the case of interbasin transfers) are often not as sensitive to allocation effects beyond the municipal boundaries of these areas. This is because municipal authorities are to a lesser extent responsible for effects outside their administrative boundaries; this could lead to misallocations of water in regional contexts. Such a situation has the potential to develop conflicting interests between different user groups. The expansion of the physical boundary of the decision-making context to include the rural periphery of the CCT should, therefore, promote more inclusive decision-making. The expansion was defined in terms secondary drainage regions sharing water resources with the CCT. This area also included some rural areas from the adjacent Breede Water Management Area, which is subjected to inter-basin transfers to the BWMA (see Fig. 3).

Table 2 presents the local municipalities apart from the CCT that were partly included in the physical expansion. 
W.J. De Lange \& T.E. Kleynhans, Int. J. Sus. Dev. Plann. Vol. 3, No. 2 (2008)

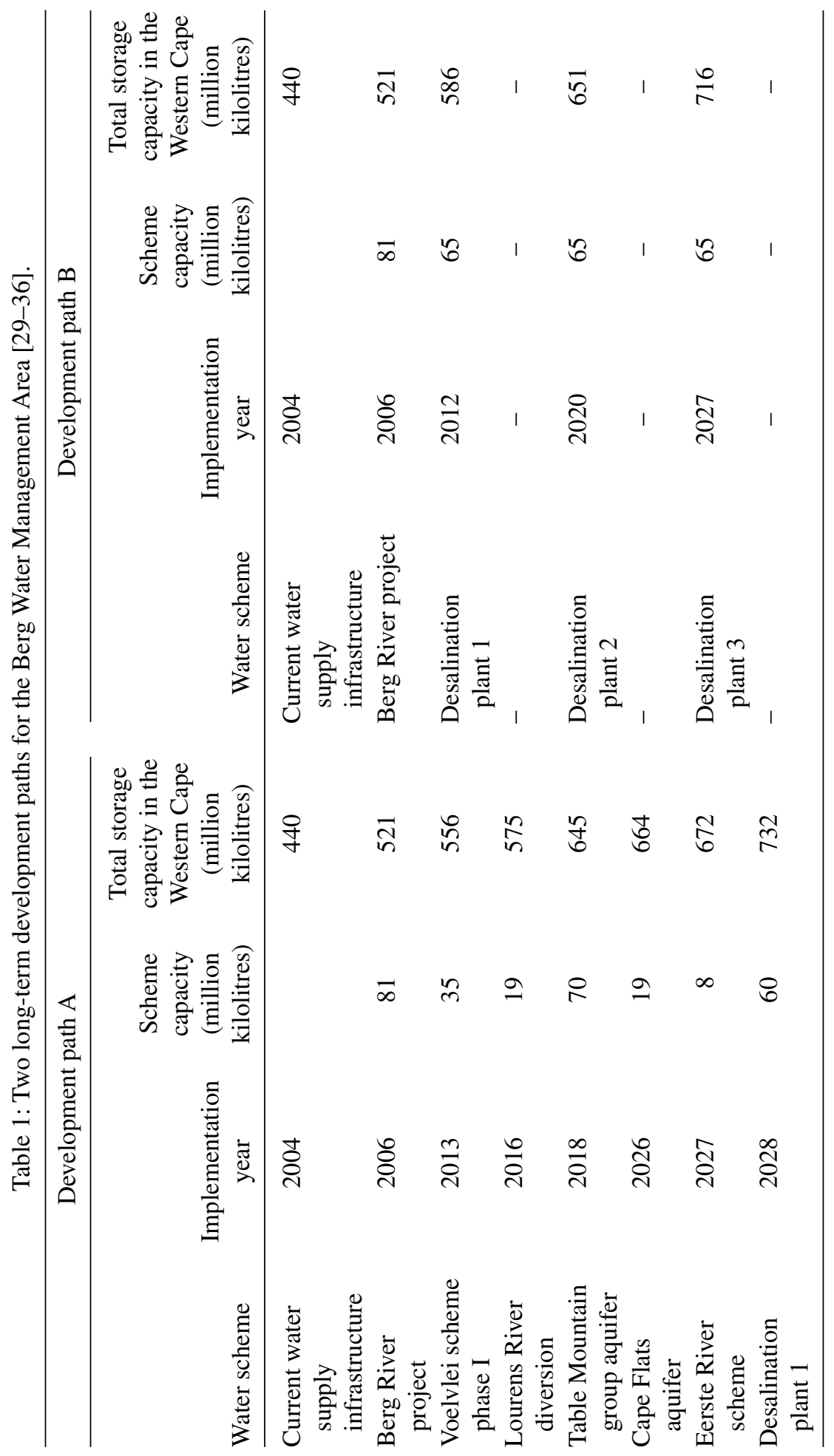




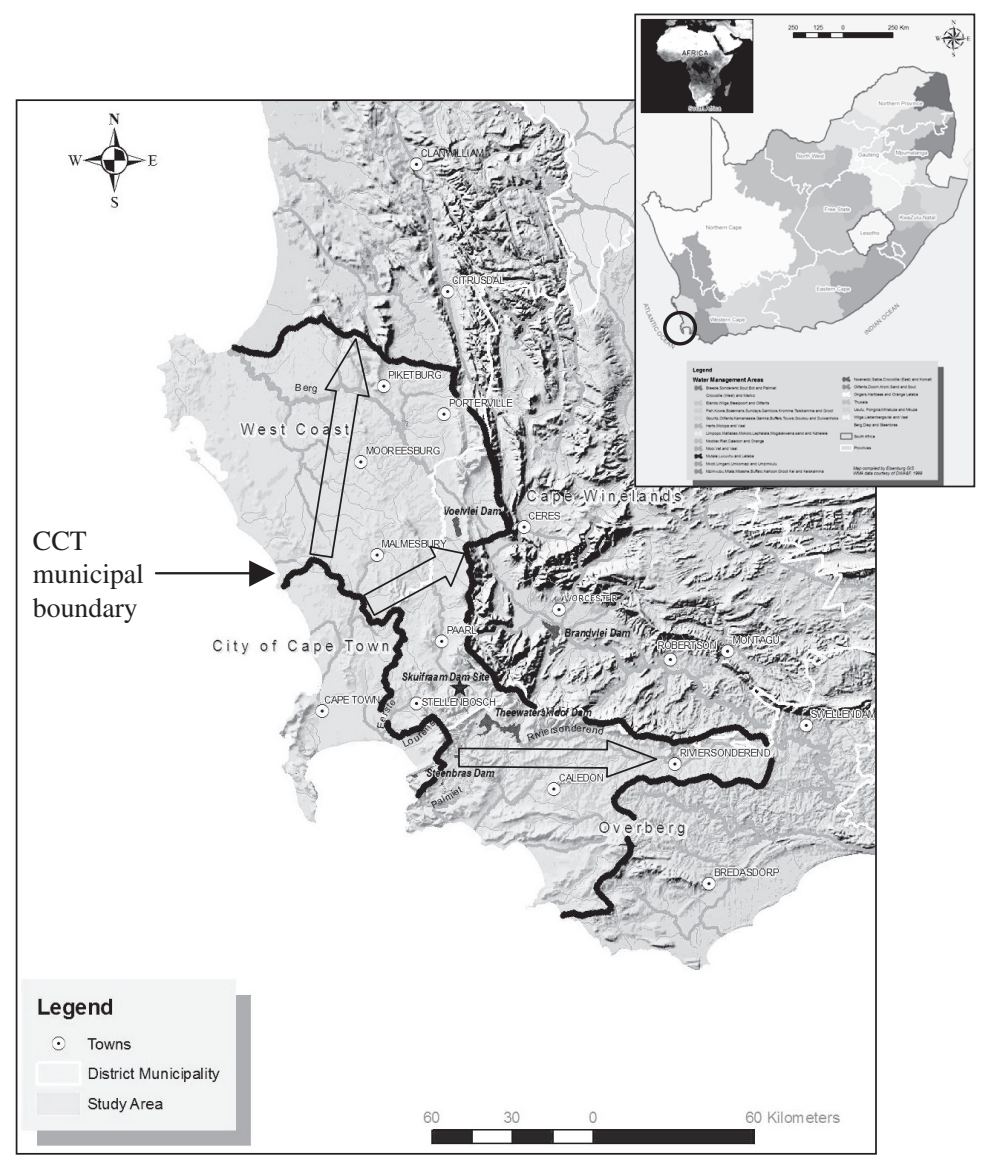

Figure 3: Physical expansion (defined in terms of secondary catchments).

Table 2: Municipal districts included in the study.

\begin{tabular}{lll}
\hline $\begin{array}{l}\text { West Coast District } \\
\text { municipality }\end{array}$ & Boland District municipality & Overberg District municipality \\
\hline $\begin{array}{l}\text { Berg River local municipality, } \\
\text { Piketberg }\end{array}$ & $\begin{array}{c}\text { Drakenstein local } \\
\text { municipality, Paarl }\end{array}$ & $\begin{array}{c}\text { Theewaterskloof local } \\
\text { municipality, Caledon }\end{array}$ \\
$\begin{array}{l}\text { Saldanha Bay local } \\
\text { municipality, Vredenburg }\end{array}$ & $\begin{array}{c}\text { Stellenbosch local } \\
\text { municipality, Stellenbosch }\end{array}$ \\
$\begin{array}{l}\text { Swartland local municipality, } \\
\text { Malmesbury }\end{array}$ & \\
\hline
\end{tabular}

Three groups were identified to legitimise both the temporal and the spatial expansions, namely public enquiry, an expert panel and decision-makers. The expert panel and the public were consulted via two surveys, while decision-makers via the accommodation of the political process running parallel to the whole process. 


\section{SURVEYS}

It was envisaged that an expert panel and the public would play different roles in the decision-making process; consequently, the need for two separate surveys was identified. The public survey focused on the identification of public preferences with regard to the two 'development paths' with the outcome to be used as input for the expert panel survey. The expert panel survey focused on determining a weighted score for the two 'development paths' to advise decision-makers. Political transparency played an important role in the development of both surveys. The study, therefore, incorporated the political process running parallel to the study, right from the inception phase. This did slow the study somewhat, but did ultimately enhance political acceptability of the research findings.

\subsection{Public survey}

Public enquiry was accommodated by means of a survey on public preference of the two development paths in the expanded decision-making context. A conjoint-analysis based approach was followed [23, 37]. This method collects and analyses individual preferences for goods and services (in this case, it was a public good: bulk-water supply service). The method assumes that each scheme may be described in terms of its characteristics or attributes to society and the natural environment. Such attributes are defined in terms of descriptive criteria, while the perceived value of each attribute is reflected by the score for such criteria. Survey questions may be asked in pairs or in the full-profile method. This study settled for a one-page full-profile presentation - just enough information was provided to enable respondents to display their preferences. This was done to keep the response rate as high as possible. The information presented was, for the aforesaid reason, focused to indicate differences between the two development paths.

Presenting a legitimate and objective view of a complex situation, in simple language, on one page, proved challenging. It was anticipated that the public would use the provided information to guide their preferences, as responses will be a function of the information and own personal perceptions and circumstances. Once again, the transparency of the questionnaire development process became important with the key stakeholders and local government participating in the development of the questionnaires. A small pilot study was done in the towns of Stellenbosch and Paarl to verify the simplicity of the questionnaire. Minor adjustments were subsequently made.

Budget limitations allowed for a stratified random sample of approximately 7000 postal questionnaires. Raw data (a database containing 607,292 registered water users in the CCT) for the urban areas were obtained from the CCT city engineers [38, 39].

Three criteria were applied to 'clean' the data:

- Since it was a postal survey, all records without a postal address were deleted.

- The data were sorted according to land-use pattern from where all non-residential uses (schools, government buildings and industries) were deleted because non-residential users do not pay according to a block tariff system and the public vote does not lie with them.

- Lastly, the data were sorted according to land value. All records with municipal values less than R50,000 were deleted because of the non-payment problem associated with such properties. All properties with municipal valuations above R3,000,0000 were also deleted because the assumption was made that these water users will probably pay their municipal accounts via debit order and will never question their water bill each month.

Approximately 195,630 data entries in 60 suburbs remained. Data from the rural areas were handled in the same way with 79,382 entries remaining after the data were cleaned. A budget 
limitation of approximately 7000 questionnaires allowed a $2.55 \%$ stratified sample. Random samples equal to the representative size of each suburb/region were drawn and a total of 7029 questionnaires went out to respondents in January 2005. The timing in terms of response rate of the survey was favourable because of a newly announced 20\% water restriction in October 2004 in almost the whole BWMA. The media also played an important role in increasing public awareness regarding water scarcity in the region. Each participant in the public survey received a cover letter introducing the reason and aim of the survey; background information and questionnaire on a single page and a return envelope. Respondents were presented with key expected impacts/ outcomes of the two developments paths (structured under the same criteria as used in the expert survey) and then asked to indicate their preference via a scoring system. It must be noted that the postal survey did not test the ability of the public to provide suggestions for long-term water management but it tested the public's preference with regard to two development paths.

\subsection{Expert panel survey}

Expert panels are not responsible for the final choice of supply augmentation scheme since their sole function is to provide a legitimate information platform upon which decision-makers can base management decisions. The expert panel, constituted by 16 individuals who served on the Cape Metropolitan Area Bulk Water Supply study [30,31], was used as a point of departure. An additional 34 individuals were identified and invited to participate. Of the 50 invitations, 17 agreed to participate in the survey.

Previous bulk water resource management studies in the BWMA [23, 26, 27, 30, 31, 33] served as a basic point of departure for the development of the information and scoring document. A criteria set as presented in Fig. 4 was developed to compare the development paths. These criteria also structured the information and scoring document. Political acceptability was critical for this part of the study, and the process was, therefore, made as transparent as possible via numerous discussions with the local Department of Water Affairs and Forestry, Department of Agriculture and the CCT Administration. The selection of comparison criteria for the two development paths is crucial for obtaining a legitimate answer. To follow a holistic approach, an extensive list of criteria was first identified. However, not all were relevant in the decision-making process, and a balance between volume of information and relevance needed to be found. It was, therefore, decided that only differentiating criteria that will distinguish the two development paths would be used, i.e. the emphasis would be placed on presenting the differences rather than the similarities between the two development paths (see Fig. 4).

Five main criteria groups, of which four consisted of sub-criteria, were identified:

- Water balance - the first sub-criterion was the relative confidence in the yield expectation, since it would heavily influence the timing of bulk supply schemes. Timing of yield (or the timely phasing of different schemes to supplement supply) was seen as an important criterion if viewed from an assurance of supply point of view, particularly if schedule one water users are considered.

- Finances - the unit reference value (URV) was included as this measure is the standard financial indicator to compare bulk supply projects. The URV is a discounted value (over the project life-time using a predetermined discount rate) per cubic metre of water for the project. This value only accounts for the capital, operational, and maintenance costs of schemes over the project lifespan. The relative confidence in the accuracy of cost estimations influences water tariff settings and therefore, also the relative weight of financial criteria as a whole. Changes in tariffs necessary to maintain the water supply services, reflect the affordability of an option or, 


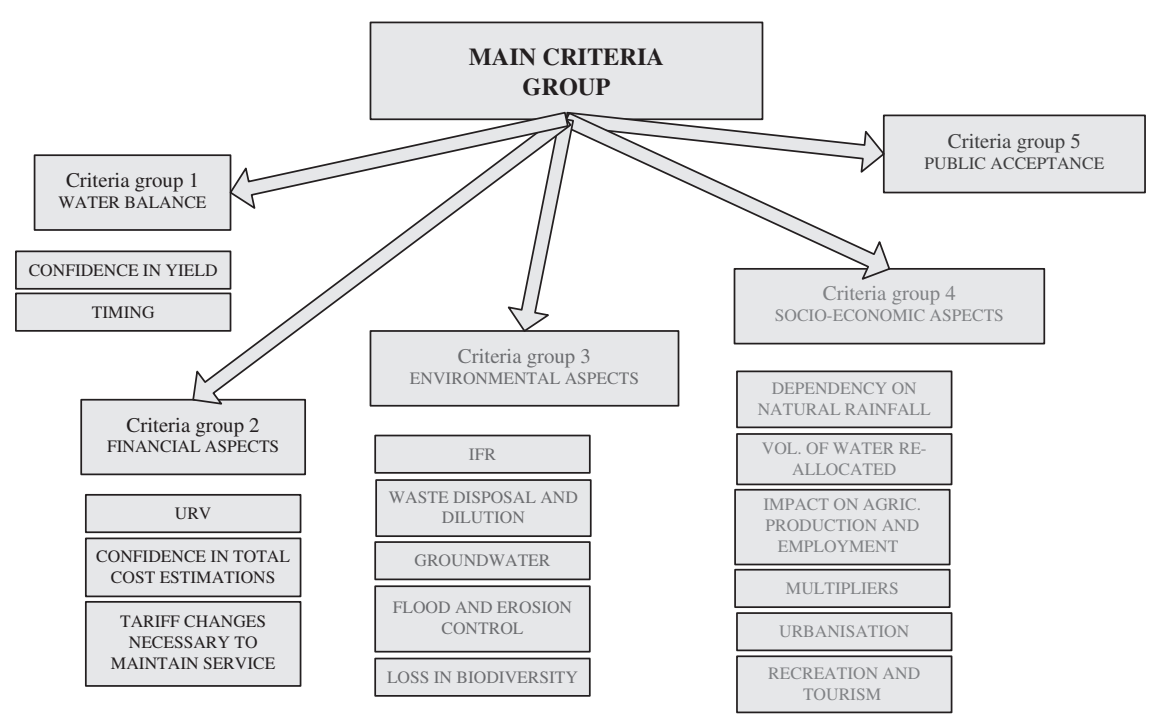

Figure 4: Criteria tree for the regional MCDM used in the study.

in this case, development path. It has an important impact on the public's acceptance of an option and eventually on the relative willingness to pay.

- Socio-economics - the dependency on natural rainfall was included to present the basic difference between the development of additional storage capacity and water production. The relative importance of agricultural irrigation in terms of water usage was accommodated by including the impacts of water restrictions (impact on agricultural production and employment) on irrigated agriculture. These impacts were pulled through to the rest of the economy by using multipliers. Urbanisation was included for its importance in population demographics as an important driver of water demand. Finally, recreation and tourism were included because of the correlation between tourism and the natural beauty of water bodies.

- The environment criteria group proved to be a controversial topic [36, 40]. Without being trapped in lengthy discussions on differing values and moralities, it was decided to include five sub-criteria. In-stream flow requirements proved to be the first and most important determinant in this section since such requirements are enforced by law; however, the quantification of the exact levels of such requirements remains. Waste disposal and the dilution effect of rivers were included because these have a direct impact on pollution as an important driver of water demand. Ground-water recharge and discharge tempos were included to focus specifically on the groundwater potential of the area. Flood and erosion control were also included; however, little scope remains for the construction of additional dams in the study area, which limits the expansion of increased flood control. The impacts on biodiversity remain rather open and were seen as the 'generic criteria' of environmental impacts.

- Public acceptance was accommodated as a separate criteria group.

Initially, the intention was to complete the expert panel survey at a series of workshops where all scoring and negotiations could be concluded. However, a modified Delphi technique via e-mail proved to be the best option. The method was originally conceived as a way to obtain the opinion of 
respondents without necessarily bringing them together face to face [41]; however, in this study face to face interviews were necessary. Participation entailed scoring the two proposed development paths in terms of a criteria tree. Respondents were asked to base their score on the presented information and their own field of expertise. The panel was also asked to indicate the relative importance of the different criteria via a weight allocation exercise. Respondents also received the public questionnaire and were asked to provide their estimation of the outcome. The e-mail session was followed by a personal consultation with each expert during which, all scores and weights were discussed and verified. Care was taken to ensure correct interpretation of questions. After completion of the interviews, all comments were compiled in a single questionnaire and used in a final follow-up e-mail session during which opportunity was given to respond to one another's comments.

\section{RESULTS}

For the public survey, the developments paths were compared only in terms of the five main criteria groups to allow for simplicity and the length of the questionnaire. Respondents were asked to indicate their preference in terms of a score out of 100 (higher score indicates higher preference).

Table 3 presents descriptive statistics for public preference and comparative expert estimations for both development paths. Of the original 7029 postal questionnaires, 1088 were returned representing a $15.48 \%$ response rate for the public survey. Expectations were slightly higher because, at the time of the survey, the BWMA was in a 100-year drought cycle accompanied by wide media coverage on the natural, socio-economic and financial impacts of the drought. A possible explanation for the response rate is that individual respondents may feel that public issues do not affect them directly, nor would their individual vote make a difference in the outcome. This corresponds with public choice theory, which holds that sound government policies in a functional

Table 3: Descriptive statistics for the public and expert panel surveys.

\begin{tabular}{lccccc}
\hline & \multicolumn{2}{c}{ Public survey } & & \multicolumn{2}{c}{ Expert estimations } \\
\cline { 2 - 3 } \cline { 5 - 6 } Descriptive statistics & $\begin{array}{c}\text { Development } \\
\text { path A }\end{array}$ & $\begin{array}{c}\text { Development } \\
\text { path B }\end{array}$ & & $\begin{array}{c}\text { Development } \\
\text { path A }\end{array}$ & $\begin{array}{c}\text { Development } \\
\text { path B }\end{array}$ \\
\hline Mean & 38.563 & 61.438 & & 44.118 & 55.882 \\
Standard error & 0.772 & 0.772 & & 4.314 & 4.314 \\
Median & 35 & 65 & & 40 & 60 \\
Mode & 40 & 60 & & 60 & 40 \\
Standard deviation & 25.473 & 25.473 & & 17.787 & 17.787 \\
Sample variance & 648.853 & 648.853 & & 316.360 & 316.360 \\
Kurtosis & -0.363 & -0.363 & & -0.923 & -0.923 \\
Skewness & 0.475 & -0.475 & & -0.431 & 0.431 \\
Range & 100 & 100 & & 60 & 60 \\
Minimum & 0 & 0 & & 10 & 30 \\
Maximum & 100 & 100 & & 70 & 90 \\
Sum & 41,956 & 66,844 & & 750 & 950 \\
Count & 1088 & 1088 & & 17 & 17 \\
\hline
\end{tabular}


democracy are an under-provided public good, because of the rational ignorance of voters: each voter is faced with an extremely small probability that his/her vote will change the result of the outcome. While gathering the relevant information necessary for a well-informed answer/vote requires time and effort, the voter could become ignorant of surveys regarding public good or even retrain from voting.

The outcome of the public questionnaire yielded a preference for development path B (and, therefore, a 'greener' water allocation strategy) by three indicators (mean, mode and median) of relative location of the data. Although both the mode and median are preferable to the mean as indicators of relative location for non-parametric data, only small differences were realised between the three measures. It was decided that the mean score of 38.56 for development path A (and 61.44 for path B) would be used in the aggregation process, which follows the expert panel survey. Mean and median expert panel estimations approximate the outcome of the public survey; however, the mode for experts were the exact opposite, indicating outliers (or possible disagreement) in expert opinion (see Table 3). Extreme care must be taken to generalise expert (and decisionmaker) insight into public preference since the outcome will always be context bound. The important point is that public preferences should be consulted and not assumed.

The expert panel survey was a detailed multi-disciplinary comparison of the development paths and followed the structure of the criteria set as described in Fig. 4. Two issues were of importance for the expert panel survey: first, the level of consensus among experts regarding the scores and criteria weights (relative importance of the differentiating criteria) and second, the weighed total score for each development path.

Normal probability plots (not shown) indicated non-normality for a significant number of criteria with a significant variation in both scores and weights (see Fig. 5). This implies a relatively low level of consensus among experts regarding the level of importance of the different criteria. However, such differences were expected since the panel is, by definition, constituted by experts from different fields of interest.

A single parameter representing each distribution of scores and weights was needed for aggregation purposes (therefore forcing normality). For the sake of comparison, the mean, mode and median were used in three separate aggregation runs for comparative calculations. Answers of the same magnitude were obtained with all three indicators displaying a majority for development path B and
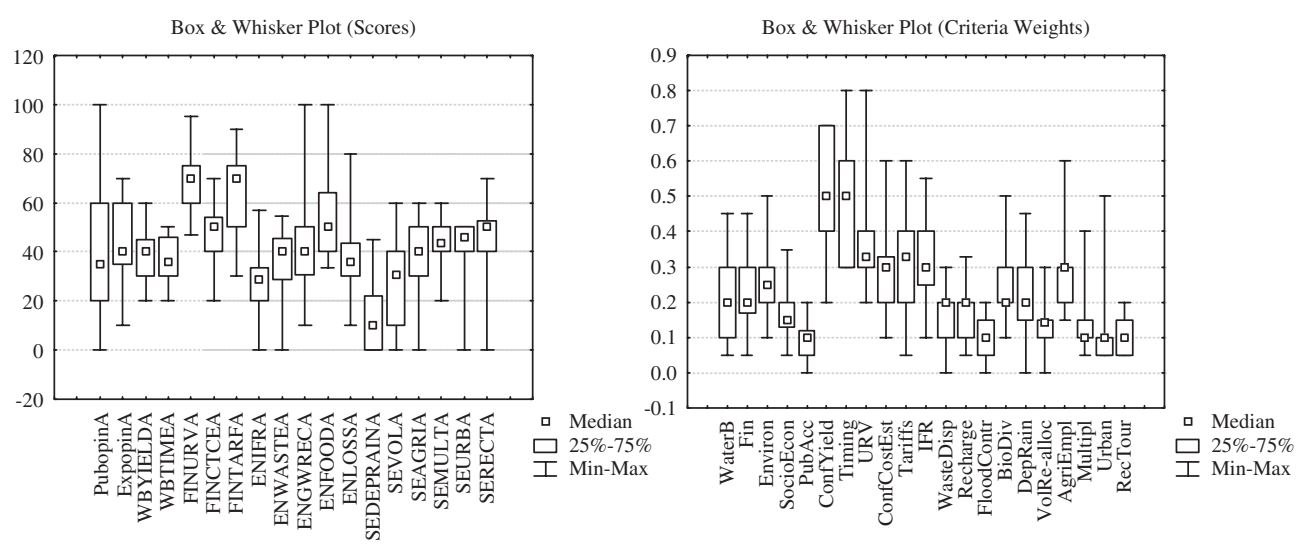

Figure 5: Box and whisker plot for scores (\%) and weights of all criteria. 


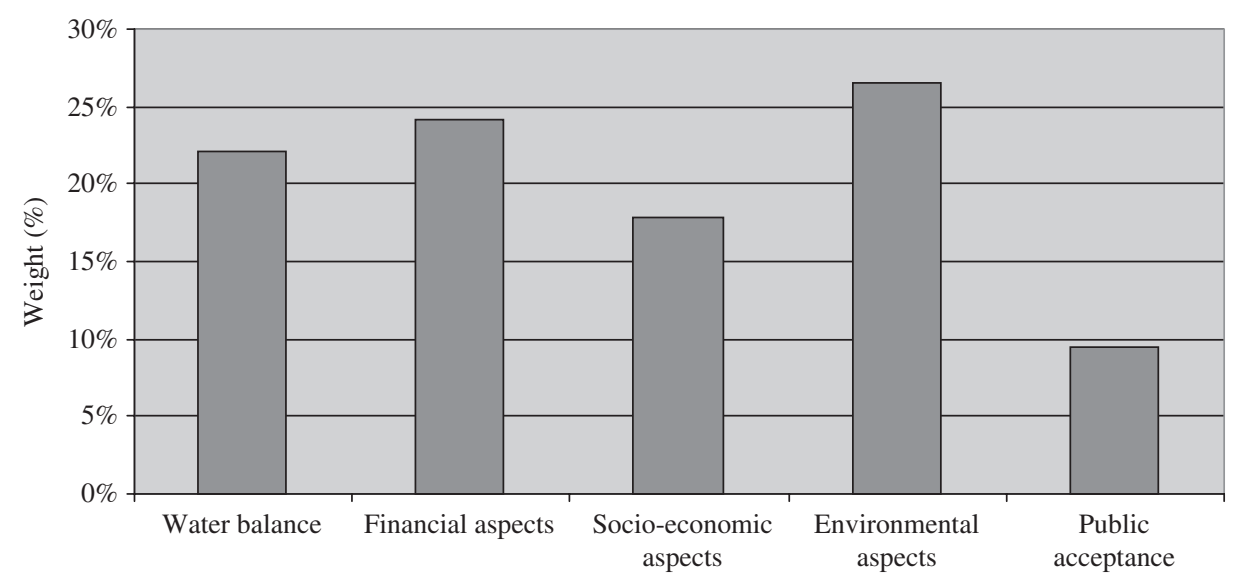

Figure 6: Mean weights: main criteria groups.

it was decided to continue with the mean scores for the aggregation process. Figure 6 presents the mean weight for each of the five main criteria groups and Fig. 7 the mean of the different sub-criteria.

A weighted score for each sub-criterion was obtained by multiplying mean scores by the mean weight of the particular sub-criterion. An aggregated total score for each development path was calculated by aggregating the weighted scores obtained from each sub-criterion (see Table 4).

A preference for development path B was noted.

\section{CONCLUSIONS}

Previous MCDM runs yielded preferences for storing capacity expansion and related bulk supply schemes. However, after expanding the decision-making context, an acceptance to water tariff increases and therefore a willingness to pay for 'greener' water was displayed, thereby suggesting that an expansion of decision-making context along with decision-support will promote social welfare, even if not all costs and benefits could be quantified in monetary terms. However, a narrow tariff resource base to absorb tariff increases could lead to an increase in non-payment problems. The increase in water tariffs for 'greener' water is a typical example of a comparison between a direct cost and an indirect benefit. The outcome is therefore an educational problem, where user education should explain that by sacrificing now, greater benefits (in the form of cost savings or benefits) might be realised in future.

A measurement problem with potentially serious consequences in terms of sustainable resource utilisation is evident in the management of public goods such as bulk-water supply infrastructure. Such a measurement problem hinders the consideration of the total costs and benefits of different long-term management options and strategies. Special reference was made to the issue of public participation as a source of the incomplete information that needs to be accounted for in the decision-making process for long-term water resource management. This could be done by confronting the public with prospective but legitimate and objective management options and by consulting their preferences. The relative success of presenting a legitimate case before public depends on the ability of making future trade-offs with the information available and to communicate a complex management problem in a simple, objective and understandable way to 


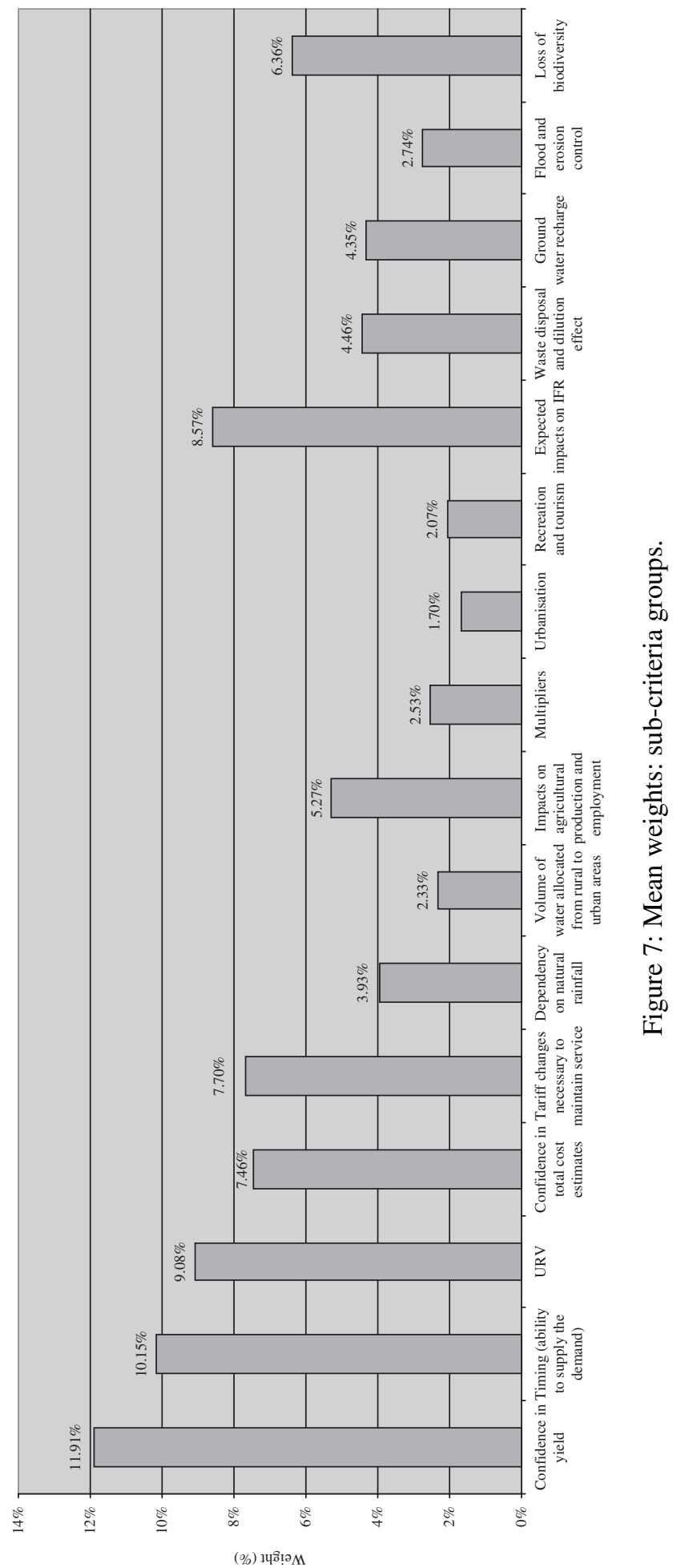




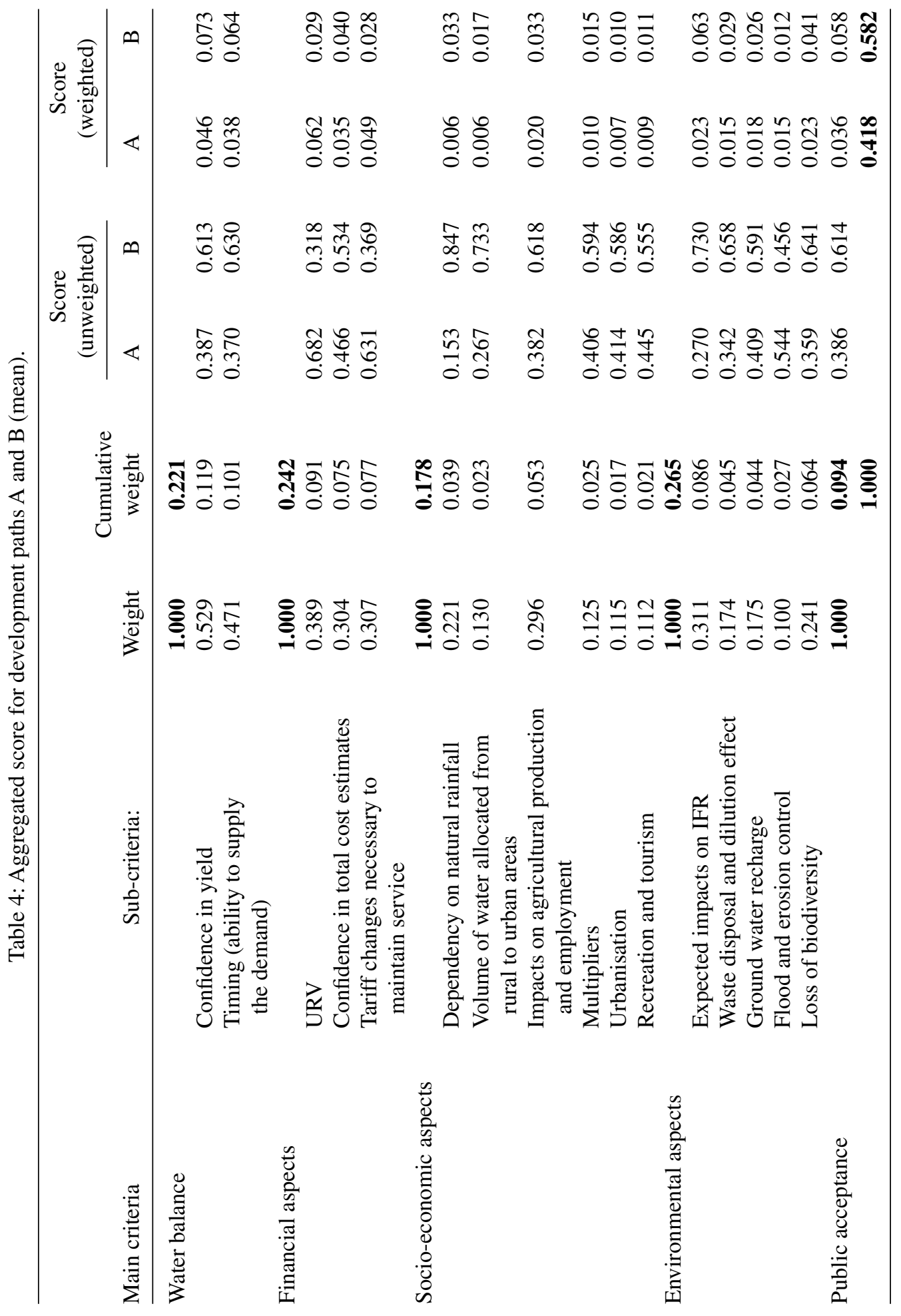


obtain a meaningful answer from the public. Political transparency promotes the legitimate presentation of such a case thereby safeguarding against bias. The challenge is to develop communication strategies that are consistent over time and space and communicate clearly and effectively. Education plays an important role in the public's ability to absorb information and present legitimate preference orderings. An educational process to promote insight into the measurement problem is therefore justified; such an education process could also improve the above-mentioned non-payment problem.

\section{REFERENCES}

[1] Carmichael, S.S., Forsyth, D. \& Hughes, D.A., Decision Support System for the Development of Rural Water Supply Schemes, Report no. 837/1/01, Water Research Commission: Pretoria, 2001.

[2] Bush, D.B., Martin, W.E. \& Brown, T.C., Do water market prices appropriately measure water values? Natural Resource Journal, 27(3), pp. 617-651, 1987.

[3] Dudley, N.J., Water allocation by markets, common property and capacity-sharing: companions or competitors? Natural Resources Journal, 32(4), pp. 757-778, 1992.

[4] Colby, B.G., Crandall, K. \& Bush, D.B., Water right transactions: market values and price dispersion. Water Resources Research, 29(6), pp. 1565-1572, 1993.

[5] Fishelson, G., The water market in Israel: an example for increasing the supply. Resource and Energy Economics, 16(4), pp. 321-334, 1994.

[6] Easter, K.W., Dinar, A. \& Rosegrant, M., Markets for Water: Potential and Performance, Kluwer Academic Press: Massachusetts, 1998.

[7] Kloezen, W., Water markets between Mexican water user associations. Water Policy, 1, pp. 437-455, 1998.

[8] Keenan, S.P., Krannich, R.S. \& Walker, M.S., Public perceptions of water transfers and markets: describing differences in water use communities. Society and Natural Resources, 12, pp. 279-292, 1999.

[9] Nieuwoudt, W.L., Water market institutions: lessons from Colorado. Agrekon, 39(1), pp. 58-67, 2000.

[10] Kumar, M. \& Singh, O., Market instruments for demand management in the face of scarcity and overuse of water in Gujarat, Western India. Water Policy, 3, pp. 387-403, 2001.

[11] Arriaza, M., Gomez-Limon, J.A. \& Upton, M., Local water markets for irrigation in southern Spain: a multi-criteria approach. Australian Journal of Agricultural and Resource Economics, 46(1), pp. 21-43, 2002.

[12] Fisher, F.M., Arlosoroff, S., Eckstein, Z., Haddadin, M., Hamati, S.G., Huber-Lee, A. \& Jarrar, A., Optimal water management and conflict resolution: The Middle East Water Project. Water Resources Research, 38(1), pp. 1-16, 2002.

[13] Louw, D.B., The Development of a Methodology to Determine the True Value of Water and the Impact of a Potential Water Market on the Efficient Utilisation of Water in the Berg River Basin, Report no. 943/1/02, Water Research Commission: Pretoria, 2002.

[14] Bateman, I.A., Lovett, A.A. \& Brainard, J.S., Applied Environmental Economics, Cambridge University Press: UK, 2003.

[15] Bergson, A., On the concept of social welfare. Quarterly Journal of Economics, 68(2), pp. 233-252, 1954.

[16] Arrow, K., Formal theories of social welfare. Collected Papers of Kenneth Arrow: Social Choice and Justice, Harvard University Press: Oxford, UK, pp. 115-132, 1984.

[17] Pearce, D.W., Economic Values and the Environment, The MIT Press: UK, 1993. 
[18] Goodstein, E.S., Economics and the Environment, Prentice Hall Publishers: New Jersey, 1999.

[19] Mander, M., Cox, D., Turpie, J. \& Breen, C., Incorporating Economic Considerations into Quantification, Allocation and Management of the Environmental Water Reserve, Report no. 978/1/02, Water Research Commission: Pretoria, 2002.

[20] Randall, A., The problem of market failure. Natural Resource Journal, 23, pp. 131-148, 1983.

[21] Livingston, M.L., Designing water institutions: market failures and institutional response. Water Resources Management, 9, pp. 203-220, 1995.

[22] Elster, J., Rational Choice, New York University Press: New York, 1986.

[23] Belton, V. \& Stewart, T.J., Multiple Criteria Decision Analysis: An Integrated Approach, Kluwer Academic Press: London, 2002.

[24] Romero, C. \& Rehman, T., Multiple-Criteria Analysis for Agricultural Decisions, Elsevier: Amsterdam, 2003.

[25] Hobbs, B., Chankong, V. \& Hamadeh, W., Does choice of multi-criteria method matter: an experiment in water resource planning. Water Resources Research, 28(7), pp. 1767-1779, 1992.

[26] Stewart, T.J., Joubert, A.R., Scott, L. \& Low, T., Multiple Criteria Decision Analysis: Procedures for Consensus Seeking in Natural Resources Management, Report no. 512/1/97, Water Research Commission: Pretoria, 1997.

[27] Stewart, T.J., Joubert, A.R. \& Liu, D., Group Decision Support Methods to Facilitate Participative Water Resource Management, Report no. 863/1/01, Water Research Commission: Pretoria, 2001.

[28] Tecle, A., Selecting a multi-criterion decision making technique for watershed resources management. Water Resources Bulletin, 28(1), pp. 129-140, 1992.

[29] City of Cape Town: Water services, Integrated Water Resource Planning and CMA Bulk Water Supply Studies, Report no. unknown, Ninham Shand and CSIR: Cape Town, 2002.

[30] Eberhard, R. \& Joubert, A.R., CMA Bulk Water Supply Study: An Evaluation of Additional Water Supply Options using MCDA, Report no. 3245/9531, Palmer Development Group and Ninham Shand Consulting Services: Cape Town, 2002.

[31] Kleynhans, S., CMA Bulk Water Supply Study: Main Report, Report no. 3245/9531, Ninham Shand Consulting Services: Cape Town, 2002.

[32] Kleynhans, S., Integration of Raw Water Sources Supplying the CMA, Report no. 3243/9690, Ninham Shand Consulting Services: Cape Town, 2002.

[33] Joubert, A., Stewart, T.J. \& Eberhard, R., Evaluation of water supply augmentation and water demand management options for the City of Cape Town. Journal of Multi-Criteria Decision Analysis, 12(1), pp. 17-25, 2003.

[34] Van Rooyen, P.C., Personal communication, Head of the Department, Western Cape Department of Agriculture, Elsenburg, 2005.

[35] Van Zyl, G., Personal communication, Department of Water Affairs and Forestry, Cape Town, 2005.

[36] Killick, M., Personal communication, City of Cape Town Administration, Water Management Services, Cape Town, 2006.

[37] Alvarez-Farizo, B. \& Hanley, N., Using conjoint analysis to quantify public preferences over the environmental impacts of wind farms: an example from Spain. Energy Policy, 30, pp. 107-116, 2002.

[38] Mostert, H., Personal communication, City of Cape Town Administration, City Engineers (Water Services), Cape Town, 2004. 
[39] Muller, J., Personal communication, City of Cape Town Administration, City Engineers (Water Services), Cape Town, 2005.

[40] Day, J., Personal communication, Department of Zoology, University of Cape Town, Cape Town, 2005.

[41] Curtis, I.A., Valuing ecosystem goods and services: a new approach using a surrogate market and the combination of a multiple criteria analysis and a Delphi panel to assign weights to the attributes. Ecological Economics, 50, pp. 163-194, 2004. 